\title{
High-Performance 3D Semiconductor-Based Heterostructure Photocatalyst in Sustained Control of Harmful Gas-Phase Pollutants Under Visible- Light Illumination
}

\section{Dong-Eun Lee}

Kyungpook National University

Mi Hyang Bae

Kyungpook National University

Wan Jo ( $\nabla$ wkjo@knu.ac.kr)

Kyungpook National University https://orcid.org/0000-0003-3255-5740

\section{Research Article}

Keywords: 3D photocatalyst, heterojunction effect, framework, sustained control, gas-phase pollutant

Posted Date: December 8th, 2021

DOI: https://doi.org/10.21203/rs.3.rs-1123468/v1

License: (c) (1) This work is licensed under a Creative Commons Attribution 4.0 International License.

Read Full License 


\section{Abstract}

Herein, a highly efficient three-dimensional (3D) semiconductor-based heterostructure photocatalyst (i.e., $\mathrm{WO}_{3}-\mathrm{g}-\mathrm{C}_{3} \mathrm{~N}_{4}$ monolithic architecture; WOCNM) was developed by immobilizing a $\mathrm{WO}_{3}-\mathrm{g}-\mathrm{C}_{3} \mathrm{~N}_{4}$

heterostructure powder on a melamine foam (MF) framework. Subsequently, the sustained control of two harmful model gas-phase pollutants (i.e., $n$-butanol and $o$-xylene) over WOCNM and selected monolithic counterparts (i.e., MF-supported $\mathrm{WO}_{3}$ monolith and MF-supported g- $\mathrm{C}_{3} \mathrm{~N}_{4}$ monolith) was investigated under visible-light irradiation. WOCNM exhibited higher photocatalytic capabilities in the sustained control of the two model pollutants than those of individual $\mathrm{WO}_{3}$ and $\mathrm{g}-\mathrm{C}_{3} \mathrm{~N}_{4}$ monoliths because the $\mathrm{WO}_{3}-\mathrm{g}-\mathrm{C}_{3} \mathrm{~N}_{4}$ heterojunction enhanced its charge-separation ability. Notably, WOCNM exhibited highly efficient photocatalytic capabilities in the sustained control of $n$-butanol (up to 97\%) and $o$-xylene (up to $86 \%)$. Moreover, no noticeable changes were observed in the WOCNM photocatalytic capability after the final run of successive applications. The fresh and successively used WOCNMs were nearly identical, and the photocatalyst powder was not observed in the reaction chamber after its successive application. As a result, WOCNM was a highly efficient and stable 3D heterostructure photocatalyst for the sustained control of gas-phase $n$-butanol and $o$-xylene, without significant catalyst powder loss. Promisingly, this study will expedite the future development of 3D photocatalysts for the sustained control of harmful gasphase pollutants.

\section{Introduction}

Air quality is crucial because it is directly related to human health and well-being [1-5]. Particularly, the inhalation exposure to $n$-butanol and $o$-xylene, which are prevalently present in various ambient environments, has been linked to a range of noxious health outcomes, including symptoms associated with carcinogenic diseases [6-8]. Accordingly, techniques need to be developed to control the aforementioned gas-phase pollutants to protect the human health and well-being.

The oxidative photocatalytic process using semiconductor catalysts has been attractively used to control a range of gas-phase pollutants, because it predominantly converts gas-phase pollutants to innoxious products under normal pressure and temperature environments [9-15]. Graphic carbon nitride $\left(\mathrm{g}-\mathrm{C}_{3} \mathrm{~N}_{4}\right)$, which is a popular visible-light-active semiconductor photocatalyst, exhibits numerous attractive advantages in the oxidative photocatalytic processes, such as outstanding chemical resistance, eminent electronic properties, and a flexible two-dimensional morphology. However, g- $\mathrm{C}_{3} \mathrm{~N}_{4}$ affords a low separation of photoinduced carriers, which induces a low quantum yield and unsatisfactory photocatalytic activity [16-18]. This disadvantage can be overcome by hybridizing the aforementioned semiconductor with other semiconductors [19-24]. Tungsten trioxide $\left(\mathrm{WO}_{3}\right)$ is a prospect semiconductor that can be appropriately hybridized with g- $\mathrm{C}_{3} \mathrm{~N}_{4}$ to yield a highly efficient $\mathrm{WO}_{3}-\mathrm{g}-\mathrm{C}_{3} \mathrm{~N}_{4}$ heterostructure for the control of harmful gas-phase pollutants because of its greatly positive valence band (VB) position and harmonic electronic structure, which affords a great oxidation potential [26-28]. 
It is further noteworthy that three-dimensional (3D) architecture photocatalysts established by immobilizing them onto a supporting substance is highly suitable for the sustained photocatalytic control of gas-phase pollutants because of the minimal loss of catalyst powders, which are easily blown away with the purified air. Therefore, herein, a $\mathrm{WO}_{3}-\mathrm{g}-\mathrm{C}_{3} \mathrm{~N}_{4}$ heterostructure was immobilized on a melamine foam (MF) framework to yield a highly efficient 3D WO $\mathrm{W}_{3}-\mathrm{g}-\mathrm{C}_{3} \mathrm{~N}_{4}$ monolithic system (WOCNM) for the sustained photocatalytic control of harmful gas-phase $n$-butanol $(n \mathrm{BT})$ and $o$-xylene $(o \mathrm{XYL})$ under visiblelight illumination. Additionally, two 3D counterparts (i.e., MF-supported $\mathrm{WO}_{3}$ monolith (WOM) and MFsupported g- $\mathrm{C}_{3} \mathrm{~N}_{4}$ monolith (CNM)) were evaluated toward the sustained photocatalytic control of the model gas-phase pollutants. Photocatalyst stability is another crucial engineering aspect for its practical applicability to pollutant control. To examine its stability, WOCNM was successively utilized for the photocatalytic control of the model pollutants. Thereafter, a systematic photocatalytic process over WOCNM was presented based on the electronic structures and active species tests.

\section{Experimental}

\subsection{Photocatalyst fabrication}

To fabricate the $\mathrm{WO}_{3}$ powder, $\mathrm{Na}_{2} \mathrm{WO}_{4} \cdot 2 \mathrm{H}_{2} \mathrm{O}(3.0 \mathrm{~g})$ and citric acid $(1.8 \mathrm{~g})$ were delivered to pure water $(120 \mathrm{~mL})$, and the solution was stirred for $15 \mathrm{~min}$. Subsequently, $\mathrm{HCl}(6 \mathrm{M})$ was dropped slowly into the above solution until its $\mathrm{pH}$ reached 1 , accompanied by the formation of a yellow precipitate. After stirring for $0.5 \mathrm{~h}$, the resultant solution was placed in an autoclave $(150 \mathrm{~mL})$, which was thermally treated at $150^{\circ} \mathrm{C}$ for $20 \mathrm{~h}$. The hydrothermally treated suspension was cooled and subjected to centrifugation. The precipitate was cleaned with pure water and conditioned at $80^{\circ} \mathrm{C}$ for $15 \mathrm{~h}$ to afford a yellow $\mathrm{WO}_{3}$ sample. Furthermore, a bulk g- $\mathrm{C}_{3} \mathrm{~N}_{4}$ powder sample was fabricated by grinding melamine $(5 \mathrm{~g})$ and then calcining at $500^{\circ} \mathrm{C}$ for $5 \mathrm{~h}$; subsequently, a sheet g- $\mathrm{C}_{3} \mathrm{~N}_{4}$ photocatalyst was obtained aftercalcining the asfabricated bulk g- $\mathrm{C}_{3} \mathrm{~N}_{4}$ powder at $550^{\circ} \mathrm{C}$ for $1.5 \mathrm{~h}$.

The $\mathrm{WO}_{3}-\mathrm{g}-\mathrm{C}_{3} \mathrm{~N}_{4}$ heterostructure was fabricated via the electrostatic assembly of the as-fabricated $\mathrm{WO}_{3}$ and $\mathrm{g}-\mathrm{C}_{3} \mathrm{~N}_{4}$ powders. Briefly, lactic acid $(20 \mathrm{~mL})$ was delivered to deionized water $(80 \mathrm{~mL})$; then, this solution was stirred for $0.5 \mathrm{~h}$. The $\mathrm{g}-\mathrm{C}_{3} \mathrm{~N}_{4}$ powder $(0.4 \mathrm{~g})$ was delivered to the solution. The dispersion was sonicated for $2 \mathrm{~h}$ and stirred for $30 \mathrm{~min}$ to afford a homogeneous solution (Solution A). Additionally, $\mathrm{WO}_{3}$ powder $(1.6 \mathrm{~g})$ was delivered to deionized water $(10 \mathrm{~mL})$; the dispersion was stirred for $0.5 \mathrm{~h}$ to yield Solution B; this solution was dropped slowly into Solution A. Subsequently, the mixture was stirred for 2 h. The mixture was centrifuged, and the resultant solid was cleaned with pure water and dried at $80^{\circ} \mathrm{C}$ for $15 \mathrm{~h}$ to yield a $\mathrm{WO}_{3}-\mathrm{g}-\mathrm{C}_{3} \mathrm{~N}_{4}$ powder.

The 3D WOCNM samples were constructed using a facile immobilization process. In summary, the assynthesized $\mathrm{WO}_{3}-\mathrm{g}-\mathrm{C}_{3} \mathrm{~N}_{4}$ powder $(0.7 \mathrm{~g})$ was delivered to deionized water $(100 \mathrm{~mL})$, and the mixture was sonicated for $10 \mathrm{~min}$ and then stirred for $0.5 \mathrm{~h}$. An MF piece ( $5 \mathrm{mg}$ ) was then dipped into the solution for $10 \mathrm{~min}$. Finally, the solution-absorbed MF was dried at $85^{\circ} \mathrm{C}$ for $10 \mathrm{~h}$ to provide the 3D WOCNM sample. 
Hereafter, the 3D WOCNM heterostructures fabricated using $0.1,0.3,0.6$, and $1.6 \mathrm{~g}$ of $\mathrm{WO}_{3}$ powder are denoted as WOCNM-0.1, WOCNM-0.3, WOCNM-0.6, and WOCNM-1.6, respectively. Moreover, the 3D WOM and 3D CNM samples were manufactured following the same method used to synthesize the 3D WOCNM but without the addition of $\mathrm{g}-\mathrm{C}_{3} \mathrm{~N}_{4}$ and $\mathrm{WO}_{3}$ powders, respectively. The sample characterizations are discussed in the Supplementary Material.

\subsection{Sustained photocatalytic control of gas-phase pollutants}

Figure S1 illustrates the photocatalytic system employed to assess the catalyst performance toward the sustained control of gas-phase $n B T$ and $0 X Y L$ under visible light. Ultra-purified air (99.9999\%) furnished by a pressurized-air cylinder was separated into two air-stream lines: one was guided to an evaporation unit, where the liquid-phase target chemicals were simultaneously introduced and evaporated for synthesizing the standard gas, and the other was delivered to a humidification unit. The two air-stream lines were merged and mixed in a heated empty chamber. The mixed gas was then transferred to a steady-stream stainless steel (SS) vessel (53 mL volume), where the test monolith was placed. Simulated sunlight was supplied using a xenon lamp $(150 \mathrm{~W})$ through a quartz window. The major photocatalytic conditions that control the model pollutants include the amount of each catalyst system (40 mg), light strength $\left(9.5 \mathrm{~mW} \mathrm{~cm}^{-2}\right)$, feed concentration of the model pollutants (1 ppm), and airstream flowrate (60 $\mathrm{mL} \mathrm{min}^{-1}$ ). To investigate the effect of the model pollutants' feed concentration on the photocatalytic capability of a representative photocatalyst (i.e., WOCNM-0.6), three other feed concentrations (i.e., 0.1 , 0.5 , and $2 \mathrm{ppm}$ ) were also investigated.

The preliminary control protocols comprised system purification, humidity equilibrium, quasi-adsorption equilibrium, and photolytic processes. The experimental system was purified by allowing ultra-pure air to flow through the system overnight under illumination. The humidity and quasi-adsorption equilibria were identified on the basis of the similarities in relative humidity and pollutant concentrations, respectively, between the input and output airstreams of the reaction vessel. The photolytic process of the model compounds was assessed via a vacant SS chamber upon irradiation. After completing the control protocols, sustained photocatalytic pollutant control tests were initiated by allowing the standard gas to flow through the reaction vessel and activating the xenon lamp. The photochemical stability of WOCNM0.6 was assessed by continuously running it five times for the control of the model pollutants.

\subsection{Measurement of the model gas-phase pollutants}

The model gas-phase pollutants were periodically measured at the inlet and outlet portions of the reaction vessel using an adsorbent tube [29]. The model pollutants ( $n \mathrm{BT}$ and oXYL) adsorbed on the sampling tube were determined using a pretreatment unit/Perkin Elmer gas chromatography/mass spectrometry (GC/MS) system. Specifically, the sampling adsorbent tube was heated at $270^{\circ} \mathrm{C}$ for $8 \mathrm{~min}$ and cooled to $-28^{\circ} \mathrm{C}$. The concentrated chemicals were then heated at $270^{\circ} \mathrm{C}$ and directed to the GC/MS unit. 
To control the quality of the chemical determinations, blank and standard samples were daily investigated. Furthermore, the daily variation of the GC/MS signals were identified and controlled. The measurement threshold values determined by investigating the standard samples were 3.4 and 3.9 for $n \mathrm{BT}$ and $\mathrm{OXYL}$, respectively.

\subsection{Measurement of active species}

Active species experiments were performed to investigate the roles of active species $\left(\mathrm{OH}^{*}, \mathrm{~h}^{+}\right.$, and $\left.\left.\mathrm{O}_{2}{ }^{--}\right)\right)$ in the WOCNM-catalyzed dye decomposition. Isopropyl alcohol $(1 \mathrm{mM})$, ammonium oxalate $(1 \mathrm{mM})$, and 1,4-benzoquinone (1 mM) were used to capture $\mathrm{OH}^{\circ}, \mathrm{h}^{+}$, and $\mathrm{O}_{2}{ }^{-}$, respectively. A 10-ppm rhodamine $\mathrm{B}$ solution was treated with the scavenger of choice and then the photocatalyst was added.

Further, the $\mathrm{OH}^{*}$ concentrations on the catalyst surface were analyzed to understand the photocatalytic reaction pathway. The $\mathrm{OH}^{*}$ concentrations were estimated by measuring 2-hydroxyterephthalic acid (HTA). Terephthalic acid $(0.05 \mathrm{~g})$ and sodium hydroxide $(0.05 \mathrm{~g})$ were transferred to distilled water $(0.6$ $\mathrm{LL})$, and then, the fabricated photocatalyst $(0.1 \mathrm{~g})$ was added. Sampling was performed under simulated sunlight exposures of 20,40 , and $60 \mathrm{~min}$, and the sample was subjected to centrifugation. The HTA population was determined using a Shimadzu RF-5301PC spectrophotometer.

\section{Results And Discussion}

\subsection{Sample characteristics}

The morphological and surface characteristics of the fabricated samples were analyzed via SEM and HRTEM. Compared to the pure MF, the three MF-supported materials (i.e., WOM, CNM, and WOCNM-0.6) comprised nanoparticles anchored on the MF framework surfaces (SEM images in Figure 1). In the HRTEM image (Figure 2a), WOCNM-0.6 exhibited excellent $\mathrm{WO}_{3}$ crystallinity and its attachment to g- $\mathrm{C}_{3} \mathrm{~N}_{4}$; the lattice distances of 0.368 and $0.328 \mathrm{~nm}$ were associated with the (200) plane of $\mathrm{WO}_{3}$ and the $(002)$ plane of $\mathrm{g}-\mathrm{C}_{3} \mathrm{~N}_{4}$, respectively $[26,30]$. Additionally, the elemental mapping image of the aforementioned material exhibited specific signs of $\mathrm{C}, \mathrm{N}, \mathrm{W}$, and $\mathrm{O}$, suggesting that $\mathrm{WO}_{3}$ and $\mathrm{g}-\mathrm{C}_{3} \mathrm{~N}_{4}$ were well hybridized (Figure 2b).

Figure 3 presents the crystal structures of pure MF, WOM, CNM, and WOCNM-0.6 via their XRD patterns. The XRD pattern of pure MF displayed no peaks, while that of WOM exhibited five prominent peaks at $23.0^{\circ}, 23.5^{\circ}, 24.2^{\circ}, 33.9^{\circ}$, and $34.8^{\circ}$, which were related to the (002), (020), (200), (022), and (202) planes of $\mathrm{WO}_{3}$, respectively [31]. The XRD pattern of $\mathrm{CNM}$ revealed a weak peak at $12.7^{\circ}$ and a prominent peak at $27.5^{\circ}$, corresponding to the (100) and (002) phases of $\mathrm{g}-\mathrm{C}_{3} \mathrm{~N}_{4}$, respectively [21, 22]. Additionally, the XRD pattern of WOCNM-0.6 revealed major reflection peaks that were associated with both $\mathrm{WO}_{3}$ and g$\mathrm{C}_{3} \mathrm{~N}_{4}$, indicating the successful hybridization of the two components. 
WOCNM-0.6 was chemically analyzed via XPS. The WOCNM-0.6 spectra illustrated the characteristic peaks of $\mathrm{W}, \mathrm{O}, \mathrm{C}$, and $\mathrm{N}$ (Figure $4 \mathrm{a}$ ), which stemmed from $\mathrm{WO}_{3}$ and $\mathrm{g}-\mathrm{C}_{3} \mathrm{~N}_{4}$. The $\mathrm{W} 4 \mathrm{f}$ spectrum comprised two eminent peaks at 35.5 and $37.5 \mathrm{eV}$, which matched the $\mathrm{W}_{4 \mathrm{f}_{7 / 2}}$ and $\mathrm{W} 4 \mathrm{f}_{7 / 2}$ of $\mathrm{WO}_{3}$ octahedral, respectively (Figure 4b) [24]. In the $01 \mathrm{~s}$ spectrum, the three peaks at 529.9, 531.0, and $533.0 \mathrm{eV}$ were related to $\mathrm{O}$ atoms, $\mathrm{W}-\mathrm{O}$ bond, and $\mathrm{W}-\mathrm{O}-\mathrm{H}$ bond in $\mathrm{WO}_{3}$, respectively (Figure $4 \mathrm{c}$ ) [24-26]. The $\mathrm{C} 1 \mathrm{~s}$ spectrum comprised two peaks at 285.1 and $288.8 \mathrm{eV}$, which were indexed to the $\mathrm{N}-\mathrm{C}=\mathrm{N}$ and $\mathrm{C}-\mathrm{C}$ groups, correspondingly (Figure 4d) [32]. Figure 4e displays four prominent peaks at 398.8, 399.8, 401.7, and $403.6 \mathrm{eV}$, which matched the $\mathrm{C}-\mathrm{N}=\mathrm{C}, \mathrm{N}-\mathrm{C}_{3}, \mathrm{C}-\mathrm{N}-\mathrm{H}$, and $\mathrm{CN}$ heterocycles, correspondingly $[26,30]$.

The surface properties of pure MF, WOM, CNM, and WOCNM-0.6 were additionally surveyed using FTIR (Figure 5). The pure MF spectrum revealed a broad absorption peak at $3325 \mathrm{~cm}^{-1}$ and a distinct peak at $806 \mathrm{~cm}^{-1}$, which were ascribed to the $\mathrm{O}-\mathrm{H}$ bond and triazine ring, respectively [33]. The WOM spectrum displayed a broad absorption peak positioned at $450-900 \mathrm{~cm}^{-1}$, which matched the vibration form of the $\mathrm{W}-0-\mathrm{W}$ group $[25,26]$. The CNM spectrum displayed several peaks at $1237-1627 \mathrm{~cm}^{-1}$, which were indexed to the $\mathrm{C}-\mathrm{N}$ bond of $\mathrm{g}-\mathrm{C}_{3} \mathrm{~N}_{4}$ [17]. Furthermore, the WOCNM-0.6 spectrum exhibited the characteristic absorption peaks of both $\mathrm{WO}_{3}$ and g- $\mathrm{C}_{3} \mathrm{~N}_{4}$, verifying the successful hybridization of the two components in this sample.

Figures 6 and S2 illustrate the UV-vis absorbance properties and converted Tauc plots of the six samples (i.e., WOM, CNM, WOCNM-0.1, WOCNM-0.3, WOCNM-0.6, and WOCNM-1.6), respectively. The CNM sample revealed visible-light absorption capability with a bandgap of $2.72 \mathrm{eV}$, which is comparable to that reported for $\mathrm{g}-\mathrm{C}_{3} \mathrm{~N}_{4}$ powder in previous studies [29, 34]; and the WOM sample revealed high visible-light absorption capability with a bandgap of $2.45 \mathrm{eV}$, which is comparable to that reported for $\mathrm{WO}_{3}$ powders in previous studies $[24,26,35]$. Moreover, the bandgaps of the four WOCNM samples (i.e., WOCNM-0.1, WOCNM-0.3, WOCNM-0.6, and WOCNM-1.6), which were determined to be intermediates between those of WOM and $\mathrm{CNM}$, increased from 2.48 to $2.65 \mathrm{eV}$ with increasing $\mathrm{WO}_{3}$ loading amount.

\subsection{Photocatalytic capabilities of 3D samples}

The photocatalytic capabilities of the three 3D samples (i.e., WOM, CNM, and WOCNM) in the sustained control of gas-phase $n \mathrm{BT}$ and $O \mathrm{XYL}$ were assessed using a steady-stream photocatalytic system under simulated sunlight irradiation. The preliminary experiments performed in the absence of either a catalyst or light revealed no noticeable control of the model pollutants. Contrarily, the illuminated photocatalysts exhibited distinctive sustained removal of the model pollutants. As shown in Figure 7, WOCNM revealed higher photocatalytic capabilities in the sustained control of $n \mathrm{BT}$ and $o \mathrm{XYL}$ than those of the individual $\mathrm{WO}_{3}$ and g- $\mathrm{C}_{3} \mathrm{~N}_{4}$ monoliths. The average sustained photocatalytic control capabilities of $n \mathrm{BT}$ and $o \mathrm{XYL}$ over WOCNM-0.6 were $81.7 \% \pm 0.6 \%$ and $62.7 \% \pm 0.5 \%$, respectively, over WOM were $19.4 \% \pm 0.4 \%$ and $8.1 \% \pm 0.3 \%$, respectively, and over CNM were $23.9 \% \pm 0.7 \%$ and $18.2 \% \pm 0.2 \%$, respectively. The enhanced photocatalytic capabilities of WOCNM- 0.6 relative to those of WOM and CNM are ascribable to the enhancement of its charge-separation ability due to the $\mathrm{WO}_{3}-\mathrm{g}-\mathrm{C}_{3} \mathrm{~N}_{4}$ heterostructure. This assertion was 
confirmed by the lower PL peak intensity of WOCNM-0.6 relative to those of WOM and CNM (Figure S3), because a low PL peak intensity denotes a low charge recombination rate [36, 37].

Notably, WOCNM exhibited highly efficient photocatalytic capabilities in the sustained control of $n \mathrm{BT}$ (up to $97 \%$ ) and $\mathrm{XYL}$ (up to $86 \%$ ) when $0.1 \mathrm{ppm}$ of the model pollutants' feed concentration was utilized (Figure 8). When their feed concentrations were decreased from 2 to $0.1 \mathrm{ppm}$, the sustained photocatalytic control capabilities of $n B T$ and $o X Y L$ gradually increased from $47-97 \%$ and from $33-86 \%$, respectively. This trend is similar to that observed in previous studies wherein the photocatalytic control capabilities of other gas-phase pollutants were investigated $[29,38]$. The feed concentration dependency is ascribed to the low competition between pollutant molecules for reactive spaces on the catalyst surface at low concentrations.

The effect of the amounts of $\mathrm{WO}_{3}$ powder loaded into $\mathrm{g}-\mathrm{C}_{3} \mathrm{~N}_{4}$ in WOCNM on its photocatalytic capability toward controlling $n \mathrm{BT}$ and $o \mathrm{XYL}$ was also evaluated. The photocatalytic capabilities of WOCNM in the sustained control of the model pollutants were in the following order: WOCNM- $0.1<$ WOCNM- $0.3<$ WOCNM-1.6 < WOCNM-0.6 (Figure 7). This suggests that an optimal $\mathrm{WO}_{3}$ amount exists for the WOCNM synthesis. This pattern of the WOCNM catalysts in the sustained photocatalytic control of the model pollutants is ascribable to their charge-separation efficiencies, which were verified by their PL peak intensities (Figure S3).

Photochemical stability analysis of WOCNM-0.6 was performed by continuously running it five times under simulated sunlight irradiation to assess its practical applicability in gas-phase pollutant control. Figure 9 displays that no noticeable changes were observed in the photocatalytic ability of the material for the target compounds control after the final run; the material retained $>98 \%$ of its original control capability. The photochemical stability of WOCNM-0.6 was also demonstrated via XRD analyses (Figure $10)$ : the XRD patterns of pristine and spent samples exhibited considerable differences. The photochemical stability of WOCNM-0.6 is ascribable to its promoted charge-transfer ability at the $\mathrm{WO}_{3}-\mathrm{g}$ $\mathrm{C}_{3} \mathrm{~N}_{4}$ interfaces, which is explained in detail in section 3.4.

\subsection{Optical characteristics of MF and MF-supported 3D photocatalysts}

Pure MF, WOM, CNM, and WOCNM-0.6 displayed white, dark-yellow, light-yellow, and yellow colors, respectively (Figure S4). According to the optical examination, the powder samples were well fixed on the MF framework in the three MF-supported 3D photocatalysts (i.e., WOM, CNM, and WOCNM-0.6); the fresh and successively used WOCNM-0.6 were nearly identical. Additionally, the photocatalyst powder was not observed in the reaction chamber after continuous applications of WOCNM-0.6. Consequently, no noticeable catalyst powder loss occurred during the photocatalytic application of the MF-supported materials. The results indicate that when MF-supported 3D architecture photocatalysts are used in the sustained photocatalytic control of gas-phase pollutants, no significant catalyst powder loss occurs.

\subsection{Systematic photocatalytic process}


A systematic photocatalytic process for controlling gas-phase pollutants over a WOCNM system was presented based on the electron diagrams of $\mathrm{WO}_{3}$ and $\mathrm{g}-\mathrm{C}_{3} \mathrm{~N}_{4}$ and their redox potentials (Figure 11). According to the Tauc plots (Figure S2) and XPS data (Figure S5), the bandgaps of $\mathrm{WO}_{3}$ and g- $\mathrm{C}_{3} \mathrm{~N}_{4}$ equaled 2.45 and $2.72 \mathrm{eV}$, respectively, their $\mathrm{VB}$ energies equaled +2.63 and $+1.52 \mathrm{eV}$, respectively. The charge-transfer pathways in WOCNM were determined by analyzing the hydroxyl radical $\left(\mathrm{OH}^{*}\right)$ populations over WOM, CNM, and WOCNM-0.6 (Figure S6). In all the samples, the $\mathrm{OH}^{\circ}$ population afforded during the photocatalytic process increased with the illumination time. Particularly, WOCNM-0.6 afforded the greatest $\mathrm{OH}^{*}$ production over the illumination period. The greater $\mathrm{OH}^{*}$ production over WOCNM-0.6 than that over WOM is due to the lower hole-electron recombination rate in the former. If the charge-transfer pathway in WOCNM- 0.6 corresponds to the heterojunction type II process, then the photoinduced holes in the $\mathrm{WO}_{3} \mathrm{VB}(+2.63 \mathrm{eV})$ might move to the $\mathrm{g}-\mathrm{C}_{3} \mathrm{~N}_{4} \mathrm{VB}(+1.52 \mathrm{eV})$ because of the lower VB potential of the latter. The transferred holes in $\mathrm{g}-\mathrm{C}_{3} \mathrm{~N}_{4} \mathrm{VB}$ could not yield $\mathrm{OH}^{*}$ because of their lower potential than the $\mathrm{OH}^{-} / \mathrm{OH}^{*}$ conversion energy $(+1.90 \mathrm{eV})$ [39].

Therefore, the greater $\mathrm{OH}^{*}$ production over WOCNM-0.6 than that over WOM is attributable to the Zscheme charge-transfer process. Thus, upon illumination of WOCNM-0.6, the photoinduced holes in the $\mathrm{WO}_{4} \mathrm{VB}$ oxidize $\mathrm{OH}^{-}$to $\mathrm{OH}^{*}$ because of its greater positive potential $(+2.63 \mathrm{eV})$ than that $\mathrm{OH}^{-} / \mathrm{OH}^{*}$. Simultaneously, electrons in the $\mathrm{WO}_{3}$ conduction band (CB) transfer to the $\mathrm{g}-\mathrm{C}_{3} \mathrm{~N}_{4}$ VB and combine with holes, whereas the electrons remaining in the $\mathrm{g}-\mathrm{C}_{3} \mathrm{~N}_{4} \mathrm{CB}$ react with oxygen and afford superoxide anion radicals $\left(\mathrm{O}_{2}{ }^{-{ }^{-}}\right)$[40]. Eventually, the resultant reactive species degrade harmful $n \mathrm{BT}$ and $o \mathrm{XYL}$ to innocuous $\mathrm{CO}_{2}, \mathrm{H}_{2} \mathrm{O}$, and other byproducts.

The Z-scheme charge-transfer process over WOCNM was further proven via active species experiments. As shown in Figure $\mathrm{S} 7, \mathrm{~h}^{+}, \mathrm{O}_{2}{ }^{--}$, and $\mathrm{OH}^{-}$are influential during photocatalysis; the greatest parameter is determined for $\mathrm{O}_{2}{ }^{--}$. If the photocatalysis matches the heterojunction type II pathway, the electrons might move from the $\mathrm{g}-\mathrm{C}_{3} \mathrm{~N}_{4} \mathrm{CB}(-1.2 \mathrm{eV})$ to the $\mathrm{WO}_{3} \mathrm{CB}(+0.18 \mathrm{eV})$ because of the potential difference between them; in such a case, the moved electrons in the $\mathrm{WO}_{3} \mathrm{CB}$ are unable to produce $\mathrm{O}_{2}{ }^{\cdot-}$ as their potential is more positive than that of the $\mathrm{O}_{2}$-to- $\mathrm{O}_{2}{ }^{\cdot-}$ reaction ( $-0.046 \mathrm{eV}$ vs. normal hydrogen electrode) [33]. Therefore, the active species experiment confirms that the photocatalytic progress over WOCNM systems occurs on the basis of the Z-scheme charge-transfer process.

\section{Conclusions}

We investigated the photocatalytic capabilities of WOCNM, which was developed by immobilizing a $\mathrm{WO}_{3}-\mathrm{g}-\mathrm{C}_{3} \mathrm{~N}_{4}$ heterostructure into an MF framework, and two monolithic counterparts (i.e., WOM and $\mathrm{CNM}$ ) in the sustained control of $n \mathrm{BT}$ and $O \mathrm{XYL}$ using a steady-stream photocatalytic system under visible light. The WOCNM sample displayed highly efficient photocatalytic performance and outstanding photochemical stability in the sustained control of $n \mathrm{BT}$ and $o \mathrm{XYL}$. The enhanced photocatalytic capabilities of WOCNM relative to those of WOM and CNM were ascribable to the enhancement of its 
charge-separation ability due to the $\mathrm{WO}_{3}-\mathrm{g}-\mathrm{C}_{3} \mathrm{~N}_{4}$ heterostructure. This assertion was confirmed by the lower PL peak intensity of WOCNM relative to those of WOM and CNM, because a low PL peak intensity denotes a low charge recombination rate. In addition, no significant catalyst powder loss was observed for the WOCNM sample successively used in the steady-stream photocatalytic system. Positively, WOCNM was a highly efficient 3D heterostructure photocatalyst for the sustained control of gas-phase $n \mathrm{BT}$ and $\mathrm{OXYL}$, without significant catalyst powder loss.

\section{Declarations}

\section{DECLARATION OF COMPETING INTEREST}

The authors declare that no conflicting actual or potential interests exist.

\section{ACKNOWLEDGEMENTS}

This work was supported by the National Research Foundation of Korea (NRF) grant funded by the Korea government (MSIT) (No. NRF-2018R1A5A1025137).

\section{References}

[1] USEPA (United States of Environmental Protection Agency, Improving Indoor Air Quality. Accessed on October 13, 2021. https://www.epa.gov/indoor-air-quality- iaq/improving-indoor-air-quality.

[2] M.U. Ali, Y. Yu, B. Yousaf, M.A.M. Munir, S. Ullah, C. Zheng, X. Kuang, M.H. Wong, Health impacts of indoor air pollution from household solid fuel on children and Women, J. Hazard. Mater. 416 (2021) 126127.

[3] M.N. Anwar, M. Shabbir, E. Tahir, M. Iftikhar, H. Saif, A. Tahir, M.A. Murtaza, M.F. Khokhar, M. Rehan, M. Aghbashlo, M. Tabatabaei, A.-S. Nizami, Emerging challenges of air pollution and particulate matter in China, India, and Pakistan and mitigating solutions, J. Hazard. Mater. 416 (2021) 125851.

[4] M. Wang, S. Jia, S.H. Lee, A. Chow, M. Fang, Polycyclic aromatic hydrocarbons (PAHs) in indoor environments are still imposing carcinogenic risk, J. Hazard. Mater. 409 (2021) 124531.

[5] Z. Nováková, J. Novák, M. Bittner, P. Čupr, P. Přiby;ová, P. Kukučka, M. Smutná, B.I. Escher, H. Demirtepe, A.Miralles-Marco, K. Hilscherová, Toxicity to bronchial cells and endocrine disruptive potentials of indoor air and dust extracts and their association with multiple chemical classes, J. Hazard. Mater. 424 (2022) 127306.

[6] W. Liang, Volatile organic compounds, odor, and inhalation health risks during interior construction of a fully furnished residential unit in Nanjing, China, Build. Environ. 186 (2020) 107366. 
[7] N. Fu, P. Wei, Y. Jia, X. Zheng, J. Guan, Indoor volatile organic compounds in densely occupied education buildings of four universities: target list, concentration levels and correlation analysis, Build. Environ. 191 (2021) 107599.

[8] D. Licina, S. Langer, Indoor air quality investigation before and after relocation to WELL-certified office buildings, Build. Environ. 204 (2021) 108182.

[9] W.A. Saoud, A. Kane, P.L. Cann, A. Gerard, L. Lamaa, L. Peruchon, C. Brochier, A. Bouzaza, D. Wolbert, A.A. Assadi, Innovative photocatalytic reactor for the degradation of VOCs and microorganism under simulated indoor air conditions: $\mathrm{Cu}-\mathrm{Ag} / \mathrm{TiO}_{2}$-based optical fibers at a pilot scale, Chem. Eng. J. 411 (2021) 128622.

[10] H. Li, K. Zhong, Z. (John) Zhai, A new double-skin façade system integrated with $\mathrm{TiO}_{2}$ plates for decomposing BTEX, Build. Environ. 180 (2020) 107037.

[11] X. Hu, C. Li, Z. Sun, J. Song, S. Zheng, Enhanced photocatalytic removal of indoor formaldehyde by ternary heterogeneous $\mathrm{BiOCl} / \mathrm{TiO}_{2}$ /sepiolite composite under solar and visible light, Build. Environ. 168 (2020) 106481.

[12] X. Li, H. Li, Y. Huang, J. Cao, T. Huang, R. Li, Q. Zhang, S.-c. Lee, W. Hi, Exploring the photocatalytic conversion mechanism of gaseous formaldehyde degradation on $\mathrm{TiO}_{2-\mathrm{x}} \mathrm{O} \mathrm{OV}$ surface, J. Hazard. Mater, 424 (2022) 127217.

[13] J. Wu, Y. Alipouri, H. Luo, L. Zhong, Ultraviolet photocatalytic oxidation technology for indoor volatile organic compound removal: a critical review with particular focus on byproduct formation and modeling, J. Hazard. Mater. 421 (2022) 126766.

[14] X. Yu, N.L. Ma, C. Sonne, R. Guan, S.S. Lam, Q.V. Le, X. Chen, Y. Yang, H. Gu, J. Rinklebe, Mitigation of indoor air pollution: a review of recent advances in adsorption materials and catalytic oxidation, $\mathrm{J}$. Hazard. Mater. 405 (2021) 124138.

[15] A. Mahmood, G. Shi, Z. Wang, Z. Rao, W. Xiao, X. Xie, J. Sun. Carbon quantum dots-TiO 2 nanocomposite as an efficient photocatalyst for the photodegradation of aromatic ring-containing mixed VOCs: an experimental and DFT studies of adsorption and electronic structure of the interface, J. Hazard. Mater. 401 (2021) 123402.

[16] C. Li, Z. Lou, Y. Yang, Y. Wang, Y. Lu, Z. Ye, L. Zhu, Hollowsphere nanoheterojunction of g- $\mathrm{C}_{3} \mathrm{~N}_{4} @ T \mathrm{TO}_{2}$ with high visible light photocatalytic property, Langmuir 35 (2019) 779-786.

[17] A. Ben-Refael, I. Benisti, Y. Paz, Transient photoinduced phenomena in graphitic carbon nitride as measured at nanoseconds resolution by step-scan FTIR, Catal. Today 340 (2020) 97-105. 
[18] B. Zhu, L. Zhang, B. Cheng, J. Yu, First-principle calculation study of tri-s-triazine- based g- $\mathrm{C}_{3} \mathrm{~N}_{4}$ : a review, Appl. Catal. B 224 (2018) 983-999.

[19] K. Wang, J. Li, G. Zhang, Ag-bridged Z-scheme 2D/2D Bi ${ }_{5} \mathrm{FeTi}_{3} \mathrm{O}_{15} / \mathrm{g}-\mathrm{C}_{3} \mathrm{~N}_{4}$ heterojunction for enhanced photocatalysis: mediator-induced interfacial charge transfer and mechanism insights, ACS Appl. Mater. Interfaces 11 (2019) 27686-27696.

[20] X. Zhou, Y. Fang, X. Cai, S. Zhang, S. Yang, H. Wang, X. Zhong, Y. Fang, In Situ photodeposited construction of Pt-Cds/g- $\mathrm{C}_{3} \mathrm{~N}_{4}-\mathrm{MnO}_{\mathrm{x}}$ composite photocatalyst for efficient visible-light-driven overall water splitting, ACS Appl. Mater Interfaces 12 (2020) 20579-20588.

[21] J. Ren, Y.Z. Wu, J.M. Pan, X.H. Yan, M. Chen, J.J. Wang, D.F. Wang, C. Zhou, Q. Wang, X.N. Cheng, Novel ternary $\mathrm{Ag} / \mathrm{CeVO}{ }_{4} / \mathrm{g}-\mathrm{C}_{3} \mathrm{~N}_{4}$ nanocomposite as a highly efficient visible-light-driven photocatalyst, $\mathrm{J}$. Adv. Ceramics 7 (2018) 50-57.

[22] H.S. EL-Sheshtawy, H.M. El-Hosainy, K.R. Shoueir, I.M. El-Mehasseb, M. El-Kemary, Facile immobilization of $\mathrm{Ag}$ nanoparticles on $\mathrm{g}-\mathrm{C}_{3} \mathrm{~N}_{4} / \mathrm{V}_{2} \mathrm{O}_{5}$ surface for enhancement of post-illumination, catalytic, and photocatalytic activity removal of organic and inorganic pollutants, Appl. Surf. Sci. 467468 (2019) 268-276.

[23] M. Tahir, M. Siraj, B. Tahir, M. Umer, H. Alias, N. Othman, Au-NPs embedded Z- scheme $\mathrm{WO}_{3} / \mathrm{TiO}_{2}$ nanocomposite for plasmon-assisted photocatalytic glycerol-water reforming towards enhanced $\mathrm{H}_{2}$ evolution, Appl. Surf. Sci. 503 (2020) 144344.

[24] R. Lei, H. Zhang, H. Ni, R. Chen, H. Gu, B. Zhang, Novel ZnO nanoparticles modified $\mathrm{WO}_{3}$ nanosheet arrays for enhanced photocatalytic properties under solar light illumination, Appl. Surf. Sci. 463 (2019) 363-373.

[25] X. Wang, M. Sun, M. Murugananthan, Y. Zhang, L. Zhang, Electrochemically self- doped $\mathrm{WO}_{3} / \mathrm{TiO}_{2}$ nanotubes for photocatalytic degradation of volatile organic compounds, Appl. Catal. B 260 (2020) 118205.

[26] S.B. Rawal, H.J. Kang, D.I. Won, W.I. Lee, Novel $\mathrm{ZnFe}_{2} \mathrm{O}_{4} / \mathrm{WO}_{3}$, a highly efficient visible-light photocatalytic system operated by a Z-scheme mechanism, Appl. Catal. B 256 (2019) 117856.

[27] H. Zhou, Z. Wen, J. Liu, J. Ke, X. Duan, S. Wang, Z-scheme plasmonic Ag decorated $\mathrm{WO}_{3} / \mathrm{Bi}_{2} \mathrm{WO}_{6}$ hybrids for enhanced photocatalytic abatement of chlorinated-VOCs under solar light irradiation, Appl. Catal. B 242 (2019) 76-84.

[28] C.-Y. Pei, Y.-G. Chen, L. Wang, W. Chen, G.-B. Huang, Step-scheme $\mathrm{WO}_{3} / \mathrm{Cdln}_{2} \mathrm{~S}_{4}$ hybrid system with high visible light activity for tetracycline hydrochloride photodegradation, Appl. Surf. Sci. 535 (2021) 147682. 
[29] Y.G. Kim, W.K. Jo, Coupling copper and hydrogenated $\mathrm{TiO}_{2}$ to bare $\mathrm{TiO}_{2}$ structures for improved photocatalytic performance, J. Am. Ceram. Soc. 101 (2018) 1479-1487.

[30] R. Bhosale, S. Jain, C.P. Vinod, S. Kumar, S. Ogale, Direct Z-scheme g- $\mathrm{C}_{3} \mathrm{~N}_{4} / \mathrm{FeWO}_{4}$ nanocomposite for enhanced and selective photocatalytic $\mathrm{CO}_{2}$ reduction under visible light, ACS Appl. Mater. Interfaces 11 (2019) 6174-6183.

[31] H. Gong, Y. Zhang, Y. Cao, M. Luo, Z. Feng, W. Yang, K. Liu, H. Cao, H. Yan, Pt@Cu $\mathrm{Cu}_{2} \mathrm{WO}_{3}$ composite photocatalyst for enhanced photocatalytic water oxidation performance, Appl. Catal. B 237 (2018) 309317.

[32] J. Dong, Y. Shi, C. Huang, Q. Wu, T. Zeng, W. Yao, A new and stable Mo-Mo $2 \mathrm{C}$ modified g- $\mathrm{C}_{3} \mathrm{~N}_{4}$ photocatalyst for efficient visible light photocatalytic $\mathrm{H}_{2}$ production, Appl. Catal. B 243 (2019) 27-35.

[33] R. Zhang, M. Ma, Q. Zhang, F. Dong, Y. Zhou, Multifunctional g- $\mathrm{C}_{3} \mathrm{~N}_{4} /$ graphene oxide wrapped sponge monoliths as highly efficient adsorbent and photocatalyst, Appl. Catal. B 235 (2018) 17-25.

[34] Q. Zhu, Y. Xuan, K. Zhang, K. Chang, Enhancing photocatalytic $\mathrm{CO}_{2}$ reduction performance of g- $\mathrm{C}_{3} \mathrm{~N}_{4}^{-}$ based catalysts with non-noble plasmonic nanoparticles, Appl. Catal. B 297 (2021) 120440.

[35] J. Yu, F. Dappozze, J. Martín-Gomez, J. Hidalgo-Carrillo, A. Marinas, P. Veroux, A. Caravaca, C. Guillard, Glyceraldehyde production by photocatalytic oxidation of glycerol on $\mathrm{WO}_{3}$-based materials, Appl. Catal. B 299 (2021) 120616.

[36] Y.C. Nie, F. Yu, L.C. Wang, Q.J. Xing, X. Liu, Y. Pei, J.P. Zou, W.L. Dai, Y. Li, S.L. Suib, Photocatalytic degradation of organic pollutants with simultaneous photocatalytic $\mathrm{H}_{2}$ evolution over graphene quantum dots $/ \mathrm{Mn}-\mathrm{N}-\mathrm{TiO}_{2} / \mathrm{g}-\mathrm{C}_{3} \mathrm{~N}_{4}$ composite catalysts: performance and mechanism, App. Catal. B 227 (2018) 312-321.

[37] W.-C. Lin, J. Jayakumar, C.-L. Chang, L.-Y. Ting, M.H. Elsayed, M. Abdellah, K. Zheng, A.M. Elewa, Y.-T. Lin, J.-J. Liu, W.-S. Wang, C.-Y. Lu, H.-H. Chou, Effect ofenergy bandgap and sacrificial agents of cyclopentadithiophene-based polymers for enhanced photocatalytic hydrogen evolution, Appl. Catal. B 298 (2021) 120577.

[38] Z. Wang, A. Mahmood, X. Xie, X. Wang, H. Qiu, J. Sun, Surface adsorption configurations of $\mathrm{H}_{3} \mathrm{PO}_{4}$ modified $\mathrm{TiO}_{2}$ and its influence on the photodegradation intermediates of gaseous o-xylene, Chem. Eng. J. 393 (2020) 124723.

[39] Z. Huang, X. Zeng, K. Li, S. Gao, Q. Wang, J. Lu, Z-Scheme $\mathrm{NiTiO}_{3} / \mathrm{g}-\mathrm{C}_{3} \mathrm{~N}_{4}$ heterojunctions with enhanced photoelectrochemical and photocatalytic performances under visible LED light irradiation, ACS. Appl. Mater. Interfaces 9 (2017) 41120-41125. 
[40] Q. Cheng, W. Yang, Q. Chen, J. Zhu, D. Li, L. Fu, L. Zhou, Fe-doped zirconia nanoparticles with highly negative conduction band potential for enhancing visible light photocatalytic performance, Appl. Surf. Sci. 530 (2020) 147291.

\section{Figures}

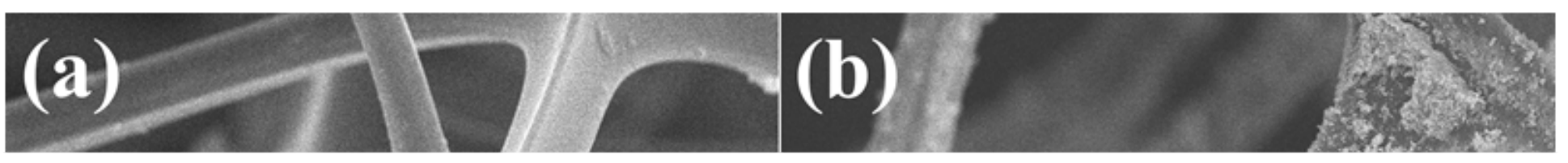

\section{Figure 1}

Scanning electron microscopy images of (a) pure MF, (b) WOM, (c) CNM, and (d) WOCNM-0.6. 


(a) (200) (b) $\mathrm{C}=\mathrm{AN}^{\mathrm{N}}$

Figure 2

(a) High-resolution transmission electron microscopy image with a corresponding selected area electron diffraction pattern (inset) and (b) energy-dispersive X-ray spectroscopy mapping of WOCNM-0.6.

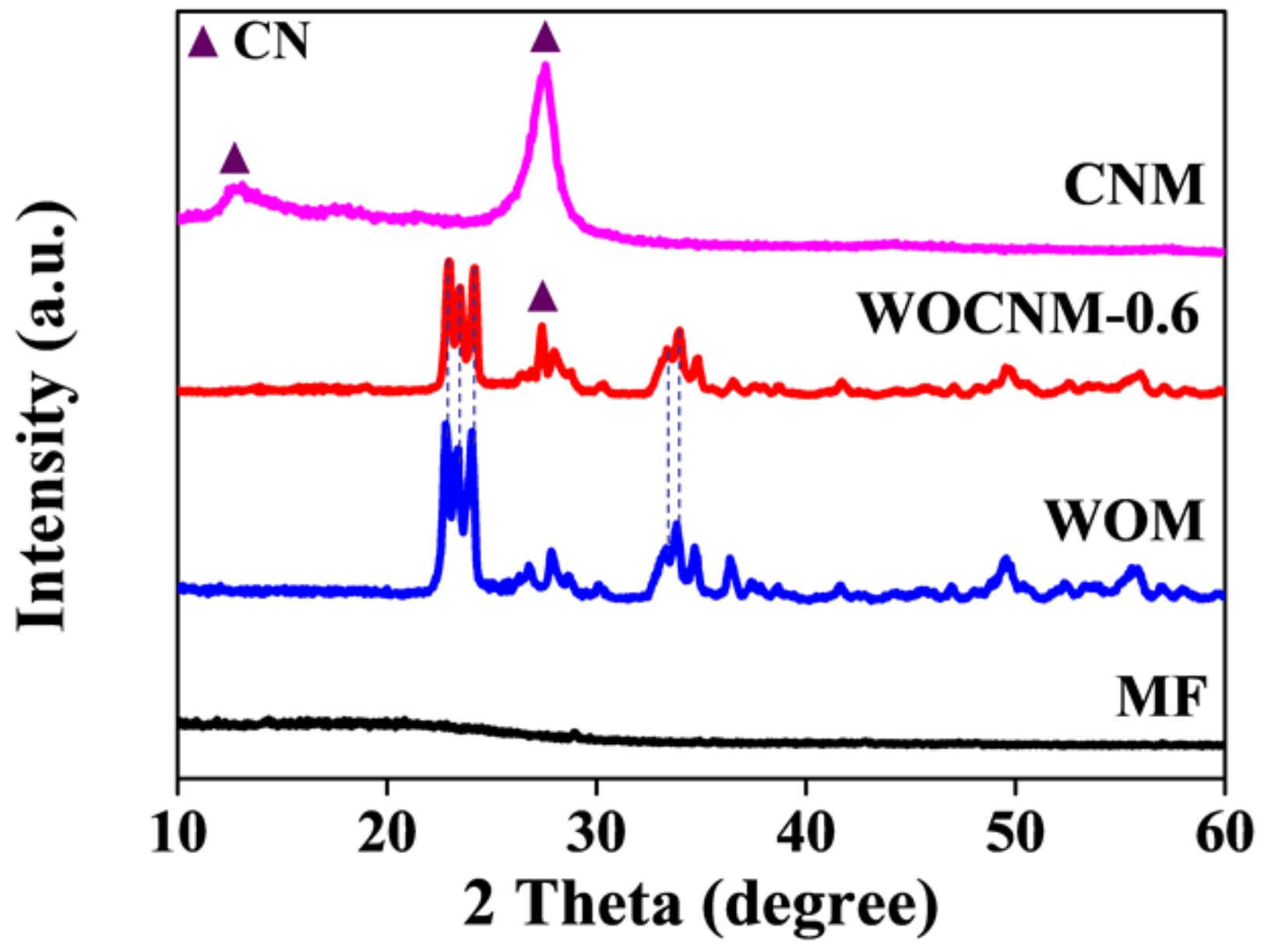

Figure 3 
X-ray diffraction patterns of pure MF, WOM, CNM, and WOCNM-0.6.
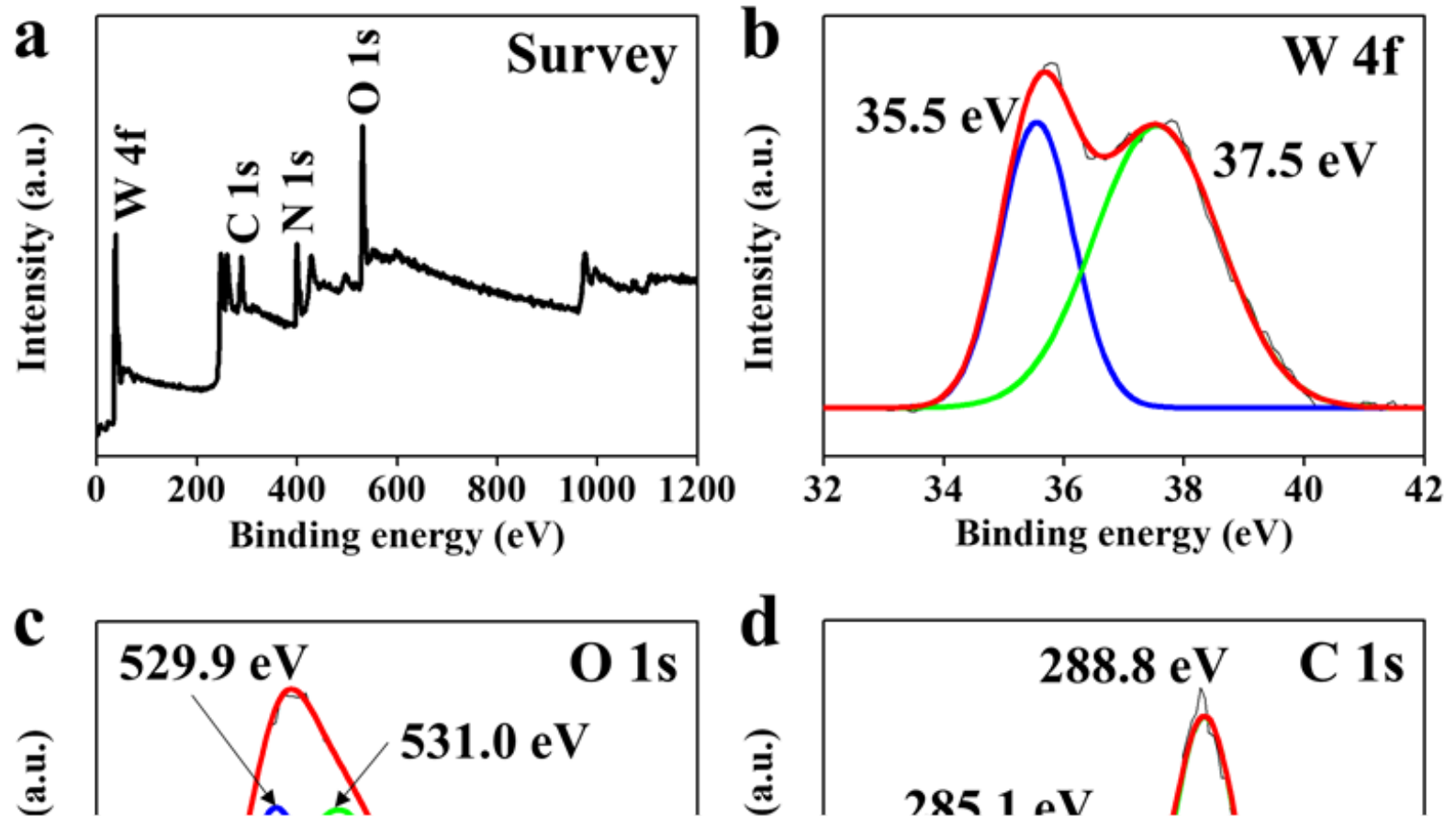

Figure 4

X-ray photoelectron spectra of WOCNM-0.6: (a) survey spectrum, (b) W 4f, (c) $01 \mathrm{~s}$, (d) C 1s, and (e) N 1s. 


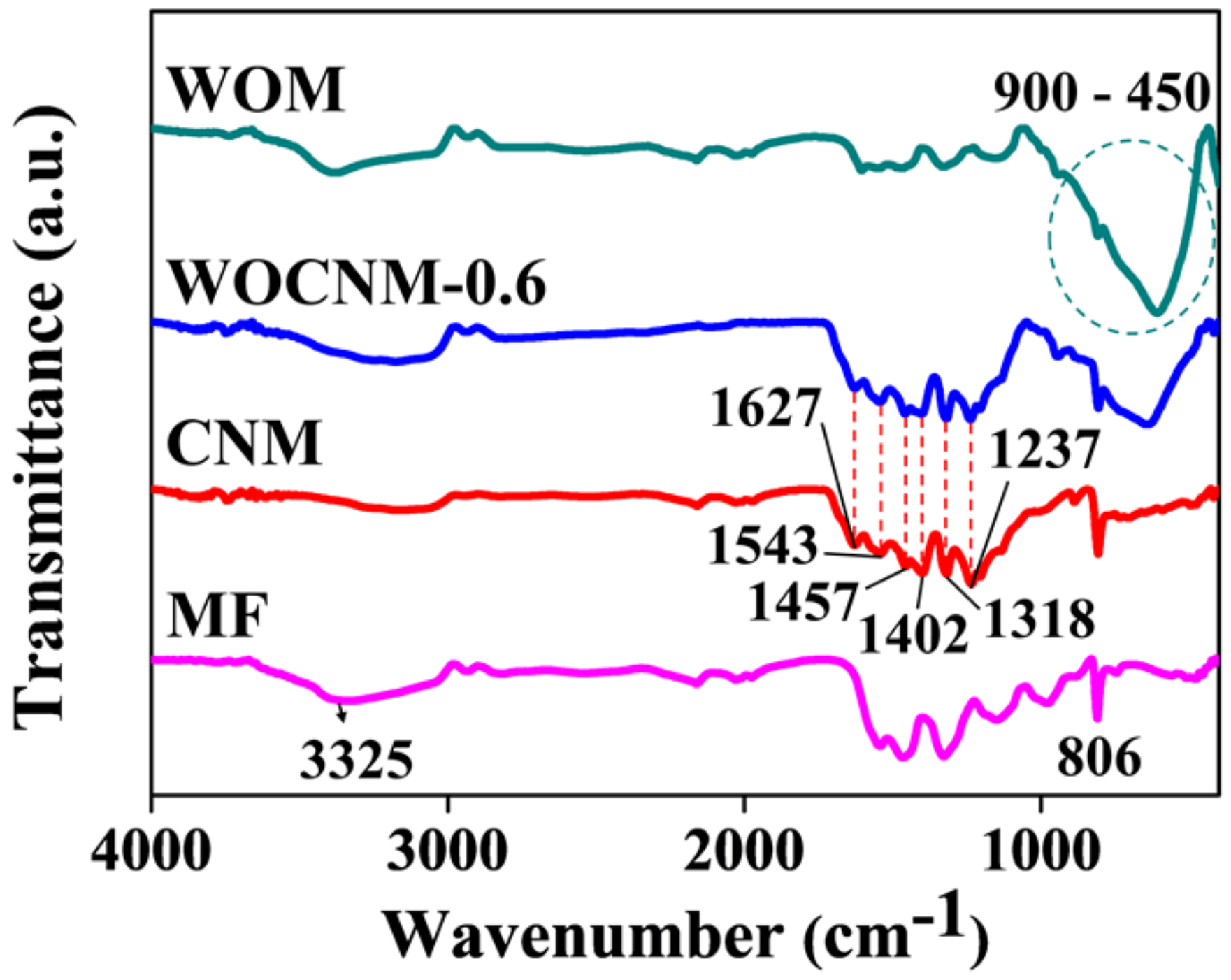

Figure 5

Fourier transform infrared spectra of pure MF, WOM, CNM, and WOCNM-0.6. 


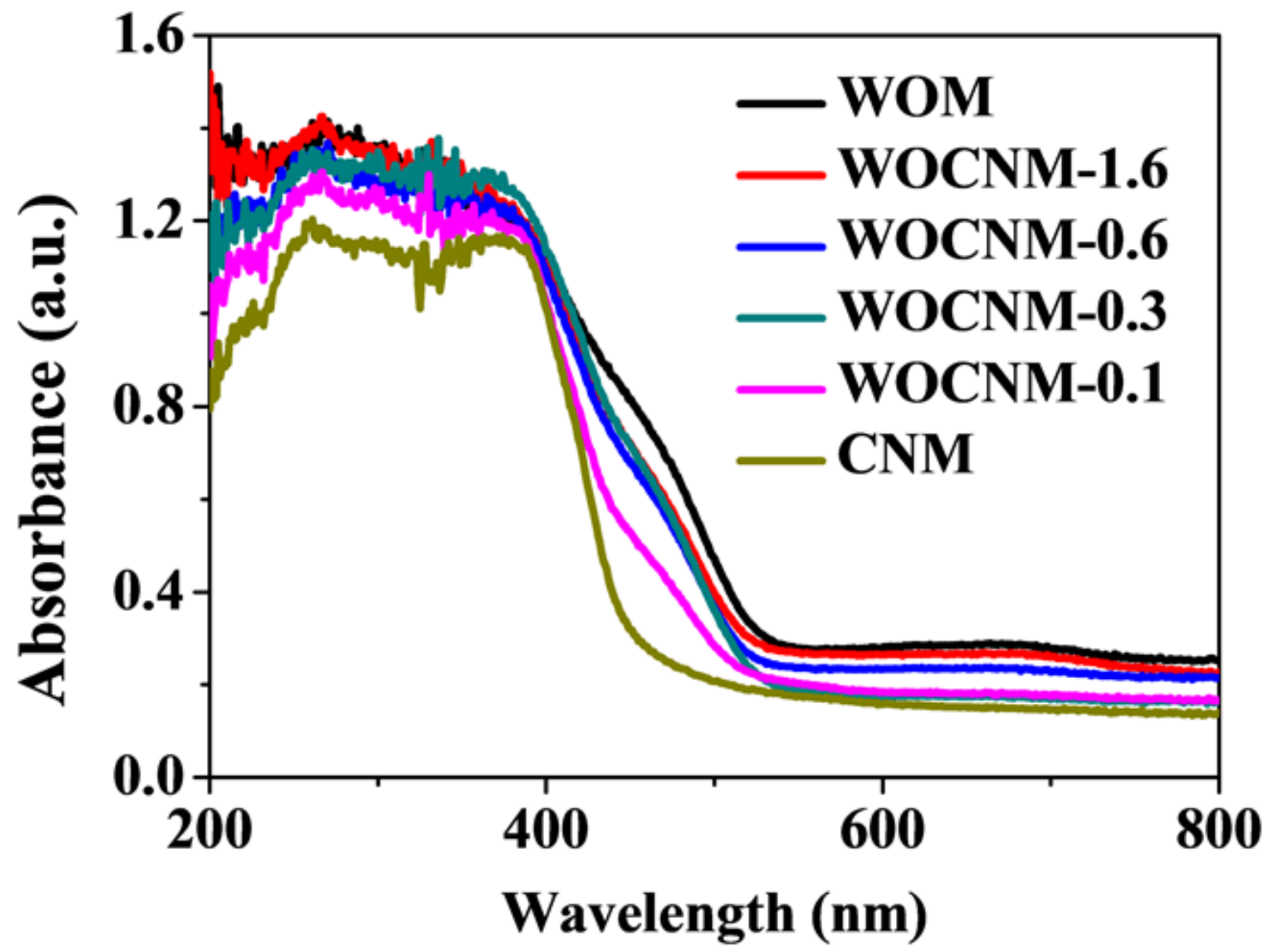

Figure 6

UV-vis absorption spectra of WOM, CNM, WOCNM-0.1, WOCNM-0.3, WOCNM-0.6, and WOCNM-1.6.
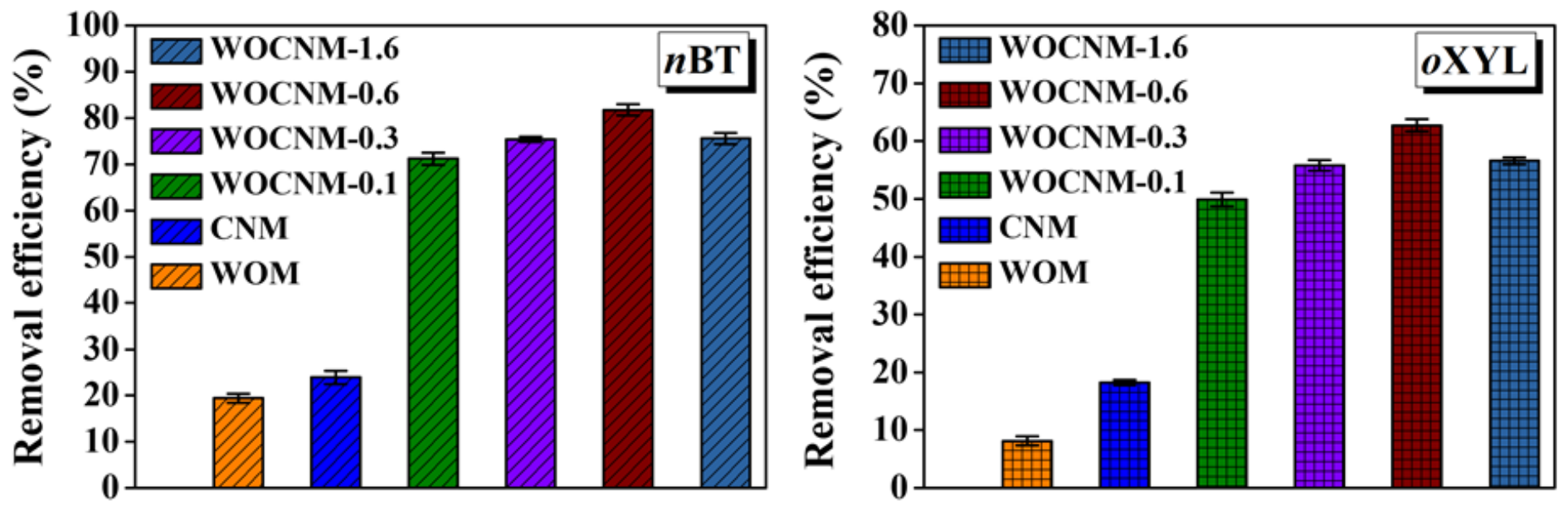

Figure 7 
Photocatalytic nBT and oXYL removal efficiencies over WOM, CNM, WOCNM-0.1, WOCNM-0.3, WOCNM0.6 , and WOCNM-1.6 under simulated sunlight irradiation.
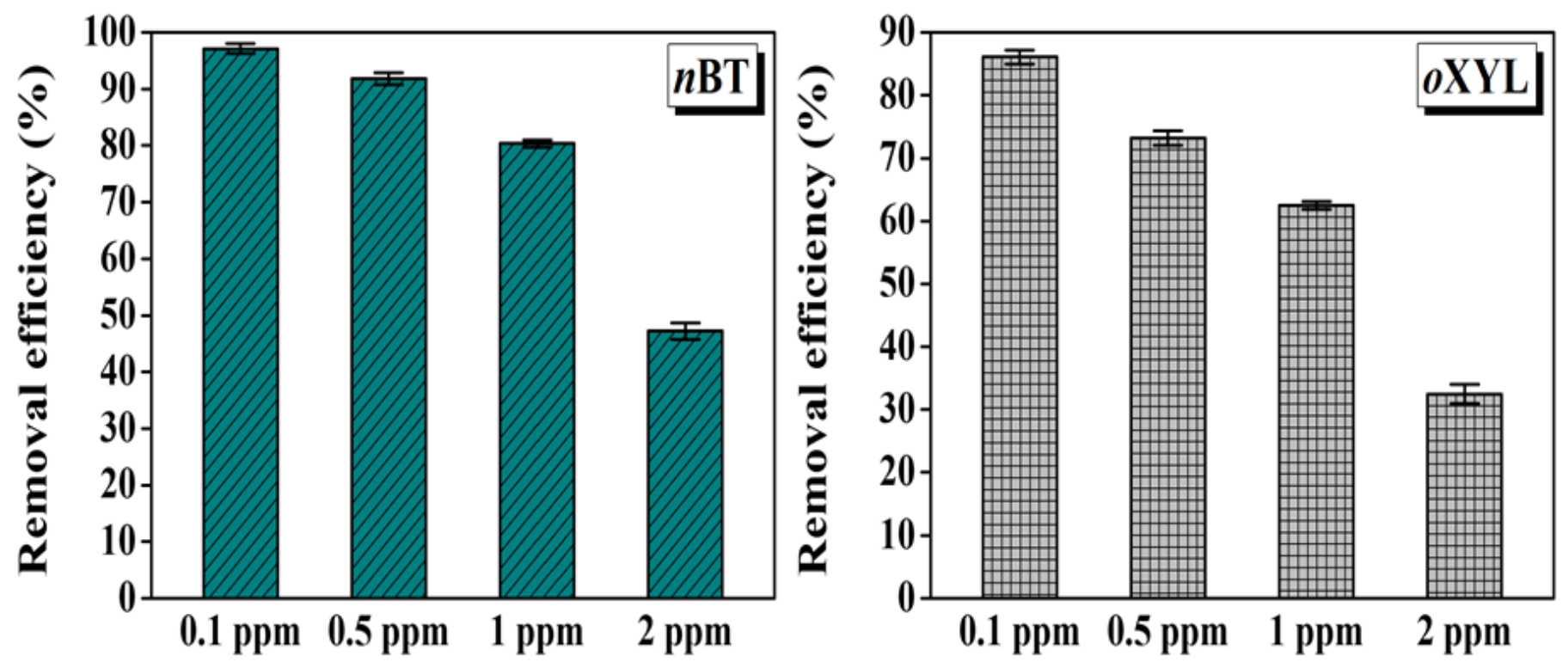

Figure 8

Photocatalytic nBT and oXYL removal efficiencies over WOCNM-0.6 according to feed concentration.
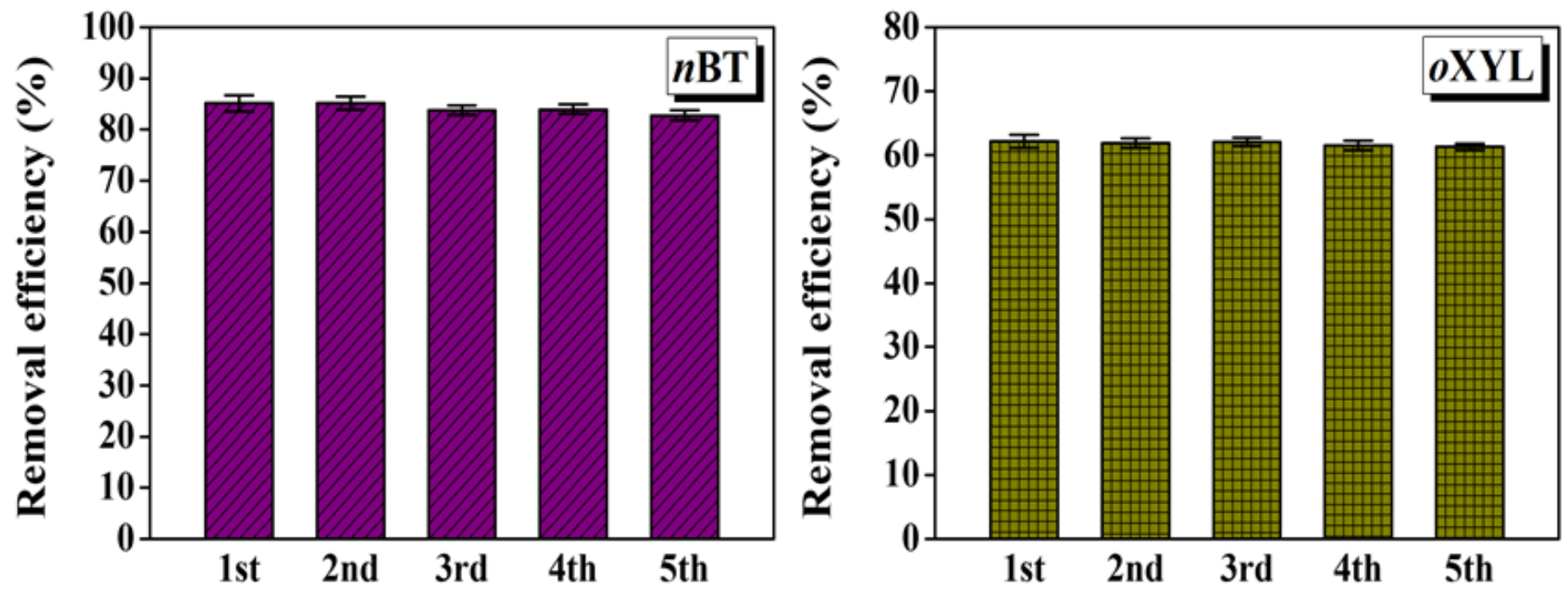

Figure 9

Photochemical stability of WOCNM- 0.6 for photocatalytic nBT and oXYL control under simulated sunlight irradiation. 


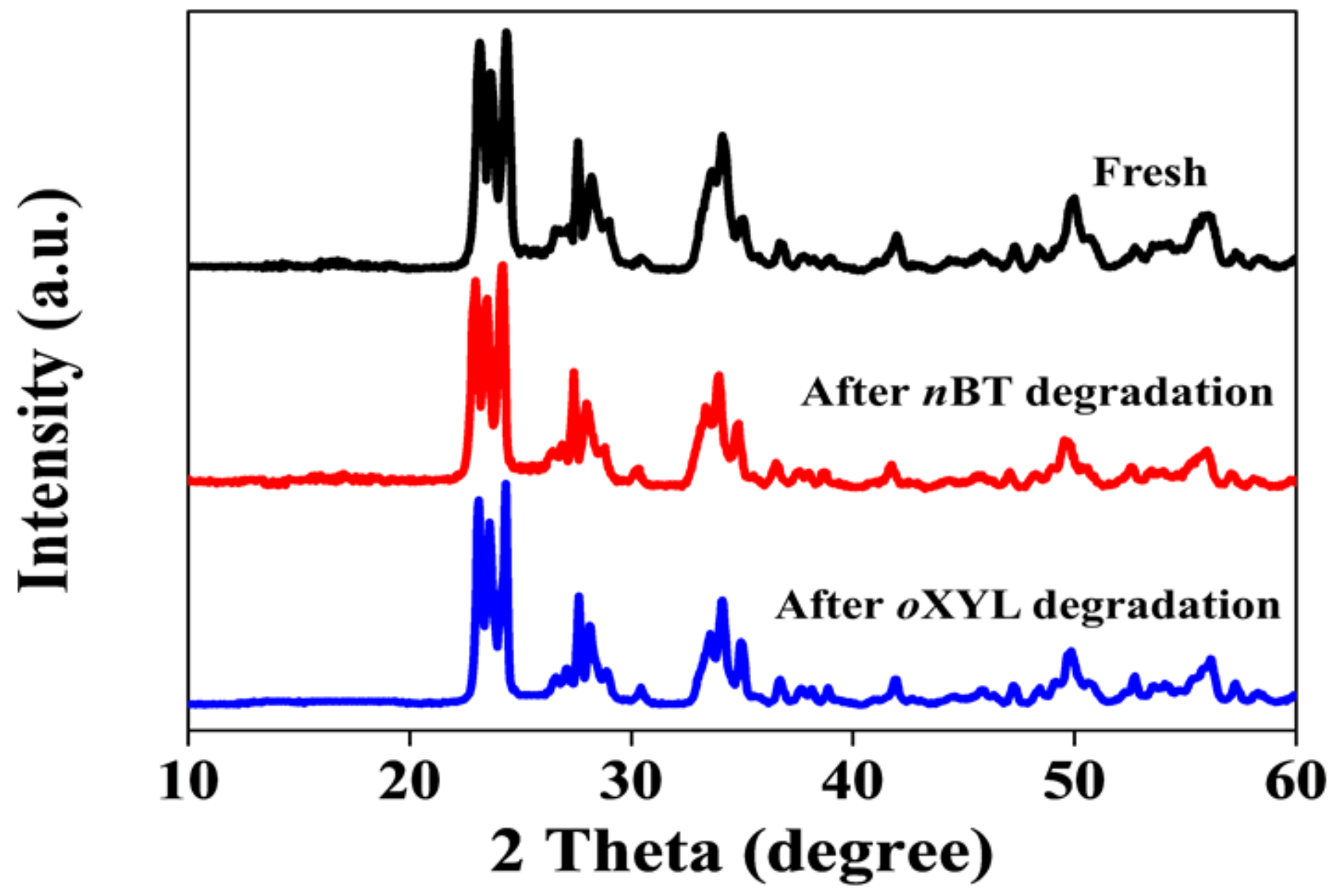

Figure 10

X-ray diffraction patterns of WOCNM-0.6 taken prior to and after recycling for the photocatalytic nBT and oXYL control. 

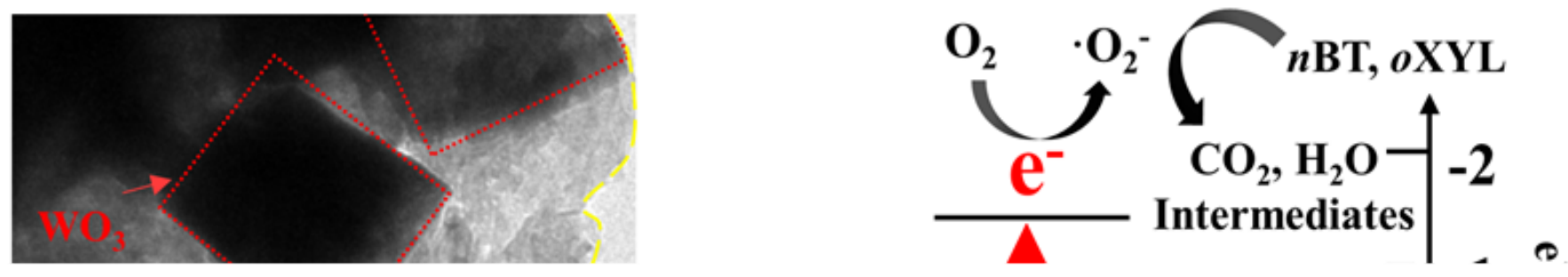

Figure 11

Systematic mechanism of photocatalytic pollutant control by WOCNM under simulated sunlight irradiation.

\section{Supplementary Files}

This is a list of supplementary files associated with this preprint. Click to download.

- SupplementaryMaterial.docx 